"NOTICE: this is the author's version of a work that was accepted for publication in Journal of Behavioral and Experimental Economics. Changes resulting from the publishing process, such as peer review, editing, corrections, structural formatting, and other quality control mechanisms may not be reflected in this document. Changes may have been made to this work since it was submitted for publication. A definitive version will subsequently be published in Journal of Behavioral and Experimental Economics, http://dx.doi.org/10.1016/i.socec.2014.07.001 “ 


\section{Highlights}

The impact of childhood sexual abuse victimhood on later life economic outcomes is examined.

CSA victimhood is found to be associated with poorer labour market outcomes.

The effects remain when we control for poor mental health.

The results are important in terms of understanding the impact of CSA. 


\title{
Childhood Sexual Abuse and Later-Life Economic Consequences
}

\author{
Alan Barrett ${ }^{1}$, Yumiko Kamiya ${ }^{2}$ \& Vincent O’ Sullivan ${ }^{3}$
}

June 2014

\footnotetext{
${ }^{1}$ Economic and Social Research Institute, Whitaker Square, Sir John Rogerson's Quay, Dublin 2, Ireland; Tel. + 3531 8632064; e-mail alan.barrett@esri.ie

${ }^{2}$ Corresponding author: Population Division, United Nations, 2 United Nations Plaza, Room DC2-1938, NY, NY 10017, USA; Tel. +1 917367 5539; e-mail kamiya@un.org

${ }^{3}$ Lancaster University Management School

Acknowledgements: We would like to acknowledge the helpful comments of James P. Smith, TILDA Seminar participants and three anonymous referees.
} 


\title{
Childhood Sexual Abuse and Later-Life Economic Consequences
}

\begin{abstract}
The impact of childhood sexual abuse (CSA) on later-life health outcomes has been studied extensively and links with depression, anxiety and self-harm have been established. However, there has been relatively little research undertaken on the possible impact of CSA on later-life economic outcomes. Here, we explore whether older people who report having experienced CSA have weaker labour force attachment and lower incomes compared to other people. We use data from The Irish Longitudinal Study on Ageing (TILDA) which is a nationallyrepresentative survey of people aged 50 and over. We find that male victims of CSA are almost three times more likely to be out of the labour force due to sickness and disability. They also have significantly lower incomes and are more likely to live alone. These effects remain even when we control for childhood economic circumstances, other adverse childhood events, current mental health difficulties and negative health behaviors. We do not find any effects for female victims. Among the policy implications are the need to be more aware of the complex effects of CSA when designing labour market activation strategies such as training for the unemployed. The results are also relevant in the legal context where compensation awards are determined.
\end{abstract}




\section{Section 1: Introduction}

Recent work by Smith and Smith (2010) and by Goodman, Joyce, and Smith (2011) has shown that mental and psychological problems experienced during childhood can have negative long-term economic consequences for the individuals in question. In the case of Goodman et al (2011), mental health problems in childhood are shown to have a much greater impact on long-run economic outcomes when compared to physical health problems. According to this research, psychological problems which occur in childhood are associated with reduced family incomes at age fifty and with reduced labour force participation throughout adulthood.

Given the evidence on the economic impact of childhood mental health, the question arises of whether victims of childhood sexual abuse (CSA) suffer long-term economic consequences arising from their trauma in childhood. It has been shown that childhood sexual abuse has long-term adverse effects that carry over into adulthood and later life (Johnson, 2004). However, much of the research on this issue has focused on long-term health consequences such as mental health, physical health and health care utilization. In this research, CSA has been shown to be associated with psychological disorders such as depression (Molnar, Buka, \& Kessler, 2001), post-traumatic stress disorder and anxiety disorder (Chen et al., 2010) and borderline personality disorder (Chartier, Walker, \& Naimark, 2007). These negative mental health outcomes have been shown to exist across all age groups. Childhood sexual abuse has also been linked to substance abuse and suicide attempts. $^{4}$

\footnotetext{
${ }^{4}$ We should note that the literature is not unanimous on the impacts of CSA. Rind and Tromovitch (1997) and Rind, Tromovitch, and Bauserman (1998) undertook meta-analytical reviews of studies in which, they argue, they differentiate between studies based on biased and nationally-representative samples. They conclude that "CSA is not associated with pervasive harm and that harm, when it occurs, is not typically intense" (1997, author abstract).
} 
In contrast to the work on health outcomes, there has been relatively little empirical research examining the impact that childhood sexual abuse might have on economic outcomes in adulthood. Hyman (2000) examined a sample of lesbian women in the U.S. and found sexual abuse to be linked to lower earnings. Robst and Smith (2008) examined the effect of CSA on women's income and found that incomes were lower only for those women who reported that the abuse had affected their lives. Currie and Widom (2010) matched data arising from court cases of childhood physical and sexual abuse with data from other survey sources on non-abused children. Comparing labour market outcomes at age 41, they found that those who had been maltreated as children were less likely to be employed and, if employed, were less likely to be in skilled or professional occupations. In addition, those who had been maltreated had lower earnings and fewer assets (for example, they were less likely to own shares in companies, a car, or a home).

As CSA is linked with mental and physical health problems later in life, it seems likely that having been a victim of CSA would also have economic implications in later adult life, for example, through withdrawal from the labour market and lower income. Previous findings indicate that adults with a history of CSA are likely to develop depression, anxiety, personality disorder, substance abuse, perceptions of poor health in adulthood, cancer, ischemic heart disease, chronic lung disease, skeletal fractures and liver disease. In turn, labour economics research finds that adults who suffer from depression earn as much as $\$ 10$ less per hour than non-depressed workers (Savoca \& Rosenheck, 2000). Depression has also been found to negatively affect sufferers' employment status (Dooley, Prause, \& HamRowbottom, 2000).

However, it is also possible the CSA might have a direct impact on economic outcomes, independent of its impact via health outcomes. Clearly, the long-run effects of traumatic childhood experiences are complex, impacting through the range of outcomes listed 
above but also potentially through traits such as self-esteem, confidence and the ability to trust.

In this paper, we examine the impact of having suffered sexual abuse as a child on later life economic outcomes using a rich data source from Ireland. As discussed in a number of official reports in Ireland in recent years, CSA was (and may still be) a disturbing feature of Irish society. These reports sought to investigate CSA in the context of the Catholic Church in Ireland and revealed widespread sexual and physical abuse in "industrial schools" controlled by Catholic religious orders from 1936 onwards (Ryan, 2009) and also sexual abuse in the community setting by members of Catholic clergy in the Archdiocese of Dublin from the 1940s to 2004 (Murphy, 2009). While both of these reports focused on the Catholic Church, McGee, Garavan, DeBarra, Byrne, and Conroy (2002) showed that in most cases the problem of CSA goes beyond the Catholic Church in that most abusers were either family members or other people known to the survivor. Of course, CSA is not just a feature of Irish life but is a disturbing and serious issue being confronted in many countries. The prevalence, depending on the definition and population used, has been estimated at between 2 percent and 62 percent for women and between 3 percent and 16 percent for men (Johnson, 2004).

There are a number of important dimensions to the analysis undertaken in this paper. First, within the economics literature the impact of negative circumstances in childhood on later life outcomes is becoming increasingly clear. However, the specific issue of CSA has been relatively under-explored and so this is an important addition. Second, as the existence and prevalence of CSA becomes more fully appreciated, there is an increasing need to understand how the victims have been affected, particularly in the long-term. Through this increased understanding, better interventions can be designed to help victims. The analysis

\footnotetext{
5 Industrial schools were residentially-based schools for neglected, orphaned and abandoned children.
} 
below may also act as an input into compensation calculations, as we attempt to quantify some dimensions of the economic impact of CSA for individuals.

The paper is structured as follows. In Section 2, we discuss the data upon which our analysis is based and also the methods which we use to explore whether or not there is a link between CSA and later-life economic outcomes. In Section 3, we present the results. In Section 4, we conclude with some observations on the importance of our results.

\section{Section 2: Data and Methods}

The data used in the analysis below come from the first wave of the Irish Longitudinal Study on Ageing (TILDA). TILDA is a nationally representative dataset containing information on over 8,000 individuals aged 50 and older and living in Ireland. The survey has been designed to mirror other longitudinal studies on ageing such as the Health and Retirement Survey (HRS) in the US, the English Longitudinal Study on Ageing (ELSA) and the pan-European Survey of Health, Ageing and Retirement in Europe (SHARE). The fieldwork for Wave 1 was completed between late 2009 and mid 2011.

The data used here were collected using two modes. First, respondents provided answers to standard socio-economic questions on issues such as age, gender, educational attainment, labour force status, income and wealth through a computer-assisted personal interview (CAPI). The second mode of data collection was a self-completed questionnaire (SCQ). This was used to obtain responses to questions of a sensitive nature, including questions about sexual abuse during childhood. The response rate for the completion of the CAPI component was $62 \%$. Of those, $82 \%$ returned SCQs, thereby providing combined CAPI and SCQ responses for over 7,000 individuals. Weights have been constructed to adjust 
for sampling techniques (stratification and clustering) and for non-response and these are used in the analysis.

We examine men and women aged less than 65 as we wish to examine labour market attachment and incomes. Apart from when presenting data in Table 1a and Table 1b, we do not analyse the outcomes of those over 65 as most of these people are no longer in the labour force and many receive social protection sources of income set by government.

The approach we take to examining whether CSA has a long-run impact on the economic outcomes of individuals involves the estimation of ordinary least squares regressions in the case of continuous outcomes variables and multinomial logistic regressions for categorical outcomes. The continuous outcomes we consider are as follows: household income, equivalized household income and individual labour income. The main categorical outcome is employment status but we also estimate models of living arrangements.

We include in all models an explanatory variable which indicates whether or not an individual was a victim of CSA and this dummy variable is constructed in the following way. In the self-completion questionnaire, respondents are asked the following two questions: (1) "Before you were 18 years old, were you ever sexually abused by either of your parents?"; (2) "Before you were 18 years old, were you ever sexually abused by anyone other than your parents?" For each event, respondents are asked to indicate whether the event occurred ("yes" or "no"), and the year in which the event occurred. If an individual responded "yes" to either of these questions, they are given a value of one for the CSA dummy variable and zero if they replied "no" or left the items unanswered". Table 1a and Table $1 \mathrm{~b}$ show the percentage of those reporting child sexual abuse by gender and age group.

\footnotetext{
${ }^{6}$ The actual incidence of non-response on these questions was very low, at 2 percent.
} 
Given the nature of CSA, there is a risk of significant under-reporting it having taken place as a result of factors such as a desire to forget unpleasant events or a sense of shame. It is difficult to provide any measure of the extent of the under-reporting, in an absolute sense, but we can at least assess whether the responses within TILDA align with another source within Ireland. McGee et al (2002) was a study which sought to investigate the prevalence of sexual abuse across all age groups and occurring at all stages of life. The formulation of questions in this report is different to that in TILDA and so comparisons are not easy. In particular, while TILDA only asked "if you were ever sexually abused", McGee et al asked about a range of forms of sexual abuse such as having been shown pornography, having been subjected to indecent exposure and having been raped. According to the TILDA data, the overall reported prevalence of CSA was $5.6 \%$ for men and $6.7 \%$ for women. From McGee et al, if we only consider people who reported having that someone had attempted to have sexual intercourse with them, the reported prevalence was 3\% for men and $4.6 \%$ for women. Based on these figures, it seems that the TILDA figures are certainly not dramatically out of line with those from McGee et al.

In addition to the CSA dummy variable, the models estimated include several additional controls relating to childhood circumstances such as childhood economic circumstances, father's education, growing up in a rural area and childhood health status as these variables may have effects on economic outcomes in later life while also being correlated with childhood sexual abuse. Childhood economic status is measured using the following question: "Now think about your family when you were growing up, from birth to age 14. Would you say your family during that time was pretty well off financially, about average, or poor?". Father's education is intended to act as a further proxy for childhood socio-economic status and is measured using a variable indicating if the respondent's father's highest level of education was primary education. Childhood health is measured using the 
following question: "Consider your health while you were growing up, from birth to age 14 . Would you say that your health during that time was excellent, very good, good, fair, or poor?" The first three categories and last two are combined to create a dummy variable.

Control variables for childhood adversity other than sexual abuse were included. Specifically, dummy variables for parental substance abuse, childhood physical abuse by parents and/or by others are included. Childhood physical abuse is asked in two questions: "Before you were 18 years old, were you ever physically abused by either of your parents?"; "Before you were 18 years old, were you ever physically abused by anyone other than your parents?". Parental substance abuse is asked as follows: "Before you were 18 years old, did either of your parents drink or use drugs so often that it caused problems in the family?".

In our models we also include measures of adversity being experienced currently. We are interested in seeing if experience of CSA has an effect on economic outcomes independent of depression, anxiety and drinking problems. A variable indicating moderate or depressive symptoms is included in the model. This is defined as having a score of 16 or more using the Centre for Epidemiological Studies Depression Scale (Radloff, 1977). CESD measures the degree to which respondents experienced a variety of depressive symptoms within the past week. Each of the 20 items are measured on a four point scale leading to a total score of 60 .

Anxiety is measured using the Hospital Anxiety and Depression Scale - Anxiety Subscale (HADS-A). This is a seven item scale generating a total score of 21 . The greater the score, the more often respondents feel anxious.

The presence of a drinking problem is measured using the CAGE questionnaire (Mayfield, McLeod, \& Hall, 1974). Respondents are asked a series of questions relating to problem alcohol drinking i.e. ever feeling they should cut down, whether other people 
criticise their drinking, ever feeling guilty about drinking, ever drinking first thing in the morning. In this paper we define problem drinking to be where the respondent agrees with two or more of the questions.

Many studies in labour economics look to control for the effects of unobserved heterogeneity. In the case of CSA, it could be argued that victims of CSA were living in environments which were which were not protective or supportive and that it was the broader environment as opposed to CSA itself that led to negative outcomes. In our analysis, we control for a range of childhood circumstances such as alcohol problems among parents, poor childhood health and poor economic circumstances. In this way, we account for some of the childhood environment but ultimately some element of unobserved heterogeneity might remain.

\section{Section 3: Results}

We begin our presentation of results by recapping on the reported prevalence of CSA in our data and also by showing the breakdown across abuse by parents and others (see Table 1a and Table 1b). While the analysis below focuses on people aged 50-64, we include older age groups in Table 1a and Table $1 \mathrm{~b}$ for the purposes of comparison. As noted above, the reported prevalence declines markedly for the oldest age group but it is difficult to interpret why this might be. It could be the result of actual lower prevalence but equally it could be the result of non-reporting. More worryingly, if childhood CSA led to earlier mortality, this would be consistent with the pattern shown in Table 1a and Table 1b. It is striking from the tables that abuse by people other than parents was much more common than abuse by parents. However, such perpetrators could include other family members such as siblings or aunts/uncles. 
In Table $2 \mathrm{a}$ and Table $2 \mathrm{~b}$ we present the descriptive statistics for all variables used in the analysis, both dependent and control, by CSA victims and others. In Table 2a we are only looking at men aged 50-64 and in Table $2 \mathrm{~b}$ we are only looking at women aged 50-64 as these people are still of working age. In relation to the respondents' recollection of childhood circumstances from birth to around age 14, male victims of CSA are found to be more likely to have come from economically poor family backgrounds relative to males who were not victims. There was no difference for females. The fathers of victims were less educated than non-victims but this difference is not statistically significant for male victims. Victims are more likely to have come from an urban area. There was no difference in childhood health for male victims of CSA versus non-victims, however female victims had worse childhood health than other females.

In relation to experiences of childhood adversity other than sexual abuse, victims of CSA are much more likely to have had parents who abused alcohol or drugs and parents who physically abused them. Victims of child sexual abuse are also more likely to have been physically abused by people other than their parents. The proportions having suffered physical abuse are dramatically higher for CSA victims, thereby suggesting environments that were generally abusive for the individuals involved.

In relation to adversity being currently experienced by the respondents, victims of child sexual abuse are more likely to have alcohol problems and more likely to exhibit anxiety and more likely to exhibit moderate or severe depressive symptoms.

For males there are no differences between the ages of victims and non-victims. However female victims were found to be slightly older.

Males reporting child sexual abuse are more educated than males who do not. This could reflect an effort on the part of some victims to overcome difficulties by becoming more 
educated but it could also be related to differential responses to the questionnaire. The higher levels of education amongst male victims of CSA relative to non-victims could be due to an increased willingness to report child sexual abuse amongst better educated people. There is no significant difference in education levels between victims and non-victims for females. In Section 4 we discuss the potential effect of differences in reporting of child sexual abuse by level of highest educational qualification on our estimates of the effect of being a victim of child sexual abuse on later life outcomes.

Turning to the dependent variables in Table $2 \mathrm{a}$, we see that male CSA victims are more likely to be sick/disabled and less likely to be currently employed. Sick/disabled is a self report and can include both physical and mental health problems which prevent people from working. In Table $2 \mathrm{~b}$ we see that female victims are more likely to be sick/disabled and less likely to be in the "other" category which is largely made up of those looking after families. We do not see differences across the two groups when looking at the income measures without adjusting for other factors.

In Table $3 \mathrm{a}$ and Table $3 \mathrm{~b}$, we move on to the presentation of our multivariate analysis. The first outcome variable that we consider is current labour force status. Based on responses to the relevant question in the questionnaire, we can categorise individuals as being in one of the following five labour market states: employed, unemployed, retired, sick/disabled and "other", where "other" includes states such as being in education, training or looking after family. As the dependent variable is a five-way categorical variable, we use a multinomial logit regression. The base outcome is employed and the results presented are odd-ratios.

The most striking result in Table $3 \mathrm{a}$ is the estimated impact of CSA on being sick/disabled as opposed to being employed for men. The estimated odd-ratios indicate that adults who had experienced CSA were 2.9 times more likely to be permanently sick or disabled as opposed to employed when compared to adults who did not experience CSA. The 
result is significant at the five percent level and so is both quantitatively large and precisely estimated. According to the estimates, having been a victim of CSA does not impact on the relative likelihoods of being employed and unemployed, retired or "other". However, it should be noted that the precise distinctions being these various states and sick/disabled may be less clear-cut than the categorization might suggest, with some element of unemployment being captured too.

A number of the other estimated odd-ratios are in line with expectations. For example, older men (within this 50-64 age band) are more likely to be retired or sick/disabled. Having a college degree makes it more likely that men are retired and less likely that they are unemployed or sick/disabled. A higher score on the anxiety scale increases the probability of being unemployed, permanently disabled/sick or other relative to being employed. In contrast to the result of CSA, we do not find any statistically significant impact of having been physically abused.

In table $3 \mathrm{~b}$ we do not see a statistically significant effect of CSA for the labour market status of women. Other variables have the expected effects. Better educated women are less likely to be unemployed, permanently disabled/sick or other relative to being employed. Older women are more likely to be retired. Women with drinking problems are more likely to be unemployed or permanently sick and disabled. Those women who had reported poor childhood health are more likely to be currently unemployed or permanently sick and disabled.

In Table 4, we move on to look at additional economic outcomes, with the focus now on incomes and earnings as opposed to labour force status. Within the TILDA questionnaire, respondents are asked about household income and an aggregate figure capturing the totality of household income, from all sources, is sought. In the first row of Table 4, we show the estimated coefficient for the CSA dummy variable from a linear regression with the log of 
household income as the dependent variable. As can be seen, for males, having been the victim of CSA has a significant negative impact on total net family income, with CSA victims living in households with incomes that are about $44 \%$ lower than comparable households. ${ }^{7}$ The coefficients for women are negative but the effects are not statistically significant for females.

As is typical in studies of household income, we also look at equivalised incomes to assess whether the pattern observed in the first row of Table 4 is the result of household structure. We use the same approach to equivalising as used by the Irish Central Statistics Office whereby the first adult is given a weight of 1 , all other adults are given a weight of 0.66 and all children are given a weight of 0.33 . The results from this regression are shown in the second row of Table 4. For men, the coefficient falls considerably but is still large and statistically significant.

In the last row of Table 4, we examine the effect of CSA on the log of labour income. For this regression, we restrict the sample to those who are employed. For men the estimated coefficient is negative (-8.1 percent), it is not statistically significant and so it is difficult to draw definitive conclusions. Similarly there is no effect for women.

The reduction in the size of the coefficient (in absolute terms) as we move from total household income to equivalised can be explained by the greater tendency for victims of CSA to live alone and not to have married. Echoing findings from elsewhere on the potential impact of CSA on relationships, in Table 5 we can see that male victims of CSA are more likely to live alone relative to living with a spouse and children. There is no effect on living arrangements for female victims of CSA.

\footnotetext{
${ }^{7}$ Goodman et al (2011) find that family incomes are reduced by 28 percent by age 50 for people who had psychological problems in childhood.
} 


\section{Section 4: Discussion}

In this paper, we have examined the association between CSA and later life economic outcomes, namely, current employment status, family income, equivalised income and individual labour income. Although the impact of childhood sexual abuse on mental health has been intensively explored, few studies have addressed the relationships between CSA and economic outcomes.

We found a large and statistically significant link between CSA and being out of employment due to being sick and/or permanently disabled for men. We also find that CSA is associated with lower household incomes and the estimated effect is large, at over 40 percent for men.

We do not find any significant effects of CSA on the later economic outcomes of women. One possible explanation could be that for many older women in Ireland, extended time out of the labour force (including permanent withdrawal upon marriage or motherhood) was the norm. Indeed, employment legislation which existed until the mid-1970s, mandated enforced withdrawal upon marriage for women working in the public sector. Therefore it may be difficult to establish meaningful empirical links between variables and labour force participation for older women. Issues such as this remain to be teased out in future research.

While our results are potentially important, we need to be clear that, as in many studies on CSA, there is a potential source of bias through the accuracy of retrospective recall (Molnar et al., 2001). As shown in the literature, the source of bias is more likely to be underreporting than over-reporting these experiences (e.g. Chen et al. (2010) \& McGee, Garavan, Byrne, O'Higgins, and Conroy (2011)). It is difficult to provide a hypothesis on whether the possible under-reporting would create an upward or downward bias in our results. It could be that people who are now doing well in life are better able to cope with past-traumas and so 
are more willing to report having been abused. If this is the case, then our results understate the true level of disadvantage of CSA victims. However, if these same people want to forget past problems in the context of later life success, then our results would over-state the disadvantage.

For male respondents, those with university education were more likely to report having been abused. This could be explained by a process through which those who were abused attempted to overcome the adversity that they faced by becoming better educated. This would result in our estimated effect of child sexual abuse being biased towards zero, with the true effect of child sexual abuse being even more negative than what we have estimated. Another possible explanation for the reporting pattern is that better educated men are more willing to report being a victim than less well educated men. If this is the case, for less well educated victims of CSA who do not report that they are victims, we are attributing their poorer labour market outcomes to their lack of education rather than to the crime which they have been a victim of. So again we have good reason to believe that the true effects of child sexual abuse are even more negative than those estimated here.

We have shown how the negative impact of CSA on labour force participation remains even when we control for depression and anxiety. This is potentially an important finding when interventions are being designed, often through state-provided training programmes or other assistance with job search. If it was thought that any labour market disadvantage suffered by victims of CSA was as a result of depression, it might be assumed that the treating of depression might "solve" any labour market problems. The results here suggest that this would not be the case. It seems that CSA affects people in ways beyond depression and anxiety and that these other effects must be understood and treated.

In the case of Ireland, a further issue arises. As activation measures are typically aimed at people on unemployment-related social assistance payments, people on disability 
payments are essentially excluded. The variable used in our analysis is based on how people report their labour force status and is not based on social assistance claims. However, on the assumption that there is a high degree of correlation between the two, the victims of CSA that we are observing may not be eligible for state-provided employment interventions. This is unfortunate because if the source of their difficulties could be identified, it should be possible to design and offer appropriate assistance.

A further policy implication arises in the context of compensation for victims of CSA. As our results show a clear and quantifiable earnings disadvantage for victims, the results could be used as an input into compensation calculations. To the extent that compensation claims are pursued through the courts, this quantification of earnings loss would be used within the legal sphere and would typically apply to individual cases. However, if a state decides to provide compensation to victims through public funds, then the use of the incomerelated results above could move from the purely legal sphere to the legal/public finance sphere. 
Tables

Table 1a: Prevalence of CSA by age group for men only

\begin{tabular}{llllll}
\hline & $\mathrm{N}$ & $\begin{array}{l}\text { Total } \\
(\%)\end{array}$ & $50-64$ & $65-75$ & $75+$ \\
\hline \hline CSA & 186 & 5.6 & 6.4 & 5.8 & 1.9 \\
CSA by parents & 19 & 0.7 & 0.7 & 0.9 & 0.4 \\
CSA by other than parents & 183 & 5.5 & 6.3 & 5.7 & 1.9 \\
\hline
\end{tabular}

16 men experienced abuse from both a parent and someone other than a parent

Table 1b: Prevalence of CSA by age group for women

\begin{tabular}{llllll}
\hline & $\mathrm{N}$ & $\begin{array}{l}\text { Total } \\
(\%)\end{array}$ & $50-64$ & $65-75$ & $75+$ \\
\hline \hline CSA & 289 & 6.7 & 9.1 & 4.8 & 2.0 \\
CSA by parents & 27 & 0.7 & 0.8 & 0.4 & 0.6 \\
CSA by other than parents & 273 & 6.2 & 8.4 & 4.8 & 1.7 \\
\hline
\end{tabular}

11 women experienced abuse from both a parent and someone other than a parent 
Table 2a: Descriptive statistics Men $<65$

CSA non-CSA p-value

Recall of childhood circumstances from birth to around age 14:

Well-off financially

Average economic circumstances

Poor economic circumstances

Father had primary education as highest level

Lived in an urban area

Health excellent, very good or good

Recall of other childhood adversity:

Parents experienced a drink/drug problem

Physically abused by parents

Physically abused by others

Current adversity:

Alcohol problem

Anxiety HADSA score

Moderate or Severe Depressive Symptoms

\section{Demographic Controls}

Age

Primary education as highest level

Secondary education as highest level

Tertiary education as highest level

\section{Economic Outcome Variables:}

Employment status

Retired

Employed

Unemployed

Permanent disabled/sick

Others

Weekly family income

Weekly individual labor income (only for employees)

$\mathrm{N}$

$$
{ }^{*} \mathrm{p}<0.10,{ }^{*} *_{\mathrm{p}}<0.05, * * * \mathrm{p}<0.01
$$

$\begin{array}{ccc}0.10 & 0.08 & 0.40 \\ 0.53 & 0.69 & <0.01 * * * \\ 0.37 & 0.23 & <0.01 * * * \\ 0.69 & 0.77 & 0.123 \\ 0.50 & 0.38 & 0.04 * * \\ 0.91 & 0.96 & 0.16\end{array}$

$\begin{array}{lll}0.20 & 0.10 & 0.019 * * \\ 0.15 & 0.02 & <0.01 * * * \\ 0.54 & 0.04 & <0.01 * * *\end{array}$

$\begin{array}{lll}0.32 & 0.20 & <0.01 * * * \\ 6.90 & 5.20 & <0.01 * * * \\ 0.40 & 0.21 & <0.01 * * *\end{array}$

$\begin{array}{lll}57.07 & 56.64 & 0.27\end{array}$

$\begin{array}{lll}0.20 & 0.26 & 0.24\end{array}$

$0.42 \quad 0.52 \quad 0.06^{*}$

$0.39 \quad 0.22<0.01 * * *$

$\begin{array}{ccc}0.17 & 0.13 & 0.32 \\ 0.53 & 0.66 & 0.02 * * \\ 0.13 & 0.12 & 0.72 \\ 0.17 & 0.08 & 0.04 * * \\ 0.00 & 0.01 & <0.01 * * *\end{array}$

$\begin{array}{lll}808.37 & 861.68 & 0.667\end{array}$

$\begin{array}{lll}826.31 & 892.37 & 0.439\end{array}$

$95 \quad 1378$ 
Table 2b: Descriptive statistics Women $<65$

\begin{tabular}{|c|c|c|c|}
\hline & CSA & non-CSA & p-value \\
\hline \multicolumn{4}{|c|}{ Recall of childhood circumstances from birth to around age 14: } \\
\hline Well-off financially & 0.09 & 0.09 & 0.99 \\
\hline Average economic circumstances & 0.68 & 0.73 & 0.20 \\
\hline Poor economic circumstances & 0.23 & 0.18 & 0.17 \\
\hline Father had primary education as highest level & 0.67 & 0.78 & $0.01 * *$ \\
\hline Lived in an urban area & 0.62 & 0.38 & $<0.01 * * *$ \\
\hline Health excellent, very good or good & 0.87 & 0.94 & $0.02 * *$ \\
\hline \multicolumn{4}{|l|}{ Recall of other childhood adversity: } \\
\hline Parents experienced a drink/drug problem & 0.26 & 0.09 & $<0.01 * * *$ \\
\hline Physically abused by parents & 0.2 & 0.03 & $<0.01 * * *$ \\
\hline Physically abused by others & 0.29 & 0.02 & $<0.01 * * *$ \\
\hline \multicolumn{4}{|l|}{ Current adversity: } \\
\hline Alcohol problem & 0.20 & 0.10 & $<0.01 * * *$ \\
\hline Anxiety HADSA score & 7.77 & 6.11 & $<0.01 * * *$ \\
\hline Moderate or Severe Depressive Symptoms & 0.48 & 0.30 & $<0.01 * * *$ \\
\hline \multicolumn{4}{|l|}{ Demographic Controls } \\
\hline Age & 56.13 & 55.86 & $0.03 * *$ \\
\hline Primary education as highest level & 0.18 & 0.21 & 0.41 \\
\hline Secondary education as highest level & 0.52 & 0.54 & 0.68 \\
\hline Tertiary education as highest level & 0.30 & 0.25 & 0.16 \\
\hline \multicolumn{4}{|l|}{ Economic Outcome Variables: } \\
\hline \multicolumn{4}{|l|}{ Employment status } \\
\hline Retired & 0.11 & 0.13 & 0.43 \\
\hline Employed & 0.54 & 0.51 & 0.55 \\
\hline Unemployed & 0.04 & 0.05 & 0.58 \\
\hline Permanent disabled/sick & 0.14 & 0.06 & $0.01 * * *$ \\
\hline Others & 0.17 & 0.25 & $0.03 * *$ \\
\hline Weekly family income & 765.42 & 775.39 & 0.667 \\
\hline Weekly individual labor income (only for employees) & 557.98 & 597.04 & 0.569 \\
\hline $\mathrm{n}$ & 163 & 1714 & \\
\hline
\end{tabular}


Table 3a: Multinomial logit model of effects of childhood sexual abuse on employment status Men $<65$ years old (employed as reference categorey)

\begin{tabular}{|c|c|c|c|c|}
\hline & Retired & Unemployed & $\begin{array}{c}\text { Permanent } \\
\text { Disabled/Sick }\end{array}$ & Others \\
\hline CSA & $\begin{array}{c}1.162 \\
(0.675)\end{array}$ & $\begin{array}{c}1.160 \\
(0.716)\end{array}$ & $\begin{array}{r}2.915^{* *} \\
(0.012)\end{array}$ & $\begin{array}{c}0.000 \\
(0.992)\end{array}$ \\
\hline \multicolumn{5}{|l|}{$\begin{array}{l}\text { Recall of childhood circumstances from } \\
\text { birth to around age 14: }\end{array}$} \\
\hline Average economic circumstances & $\begin{array}{c}1.193 \\
(0.568)\end{array}$ & $\begin{array}{c}0.831 \\
(0.597)\end{array}$ & $\begin{array}{r}1.015 \\
(0.973)\end{array}$ & $\begin{array}{c}1.056 \\
(0.961)\end{array}$ \\
\hline Poor economic circumstances & $\begin{array}{c}1.592 \\
(0.185)\end{array}$ & $\begin{array}{c}1.581 \\
(0.219)\end{array}$ & $\begin{array}{l}0.945 \\
(0.905)\end{array}$ & $\begin{array}{c}1.951 \\
(0.574)\end{array}$ \\
\hline $\begin{array}{l}\text { Father had primary education as highest } \\
\text { level }\end{array}$ & $\begin{array}{c}0.914 \\
(0.667)\end{array}$ & $\begin{array}{c}1.338 \\
(0.222)\end{array}$ & $\begin{array}{c}0.821 \\
(0.492)\end{array}$ & $\begin{array}{c}0.619 \\
(0.458)\end{array}$ \\
\hline Lived in an urban area & $\begin{array}{c}1.746^{* * *} \\
(0.002)\end{array}$ & $\begin{array}{c}1.605 * * * \\
(0.010)\end{array}$ & $\begin{array}{c}1.324 \\
(0.224)\end{array}$ & $\begin{array}{c}0.937 \\
(0.911)\end{array}$ \\
\hline Health excellent, very good or good & $\begin{array}{c}0.629 \\
(0.256)\end{array}$ & $\begin{array}{c}1.178 \\
(0.711)\end{array}$ & $\begin{array}{c}0.586 \\
(0.211)\end{array}$ & $\begin{array}{c}0.776 \\
(0.817)\end{array}$ \\
\hline \multicolumn{5}{|l|}{ Recall of Childhood Adversity: } \\
\hline Parents experienced a drink/drug problem & $\begin{array}{c}1.406 \\
(0.211)\end{array}$ & $\begin{array}{l}1.647^{*} \\
(0.053)\end{array}$ & $\begin{array}{c}1.021 \\
(0.956)\end{array}$ & $\begin{array}{c}0.792 \\
(0.825)\end{array}$ \\
\hline Physically abused by parents & $\begin{array}{l}1.461 \\
(0.241)\end{array}$ & $\begin{array}{c}0.921 \\
(0.826)\end{array}$ & $\begin{array}{c}0.583 \\
(0.255)\end{array}$ & $\begin{array}{c}0.000 \\
(0.991)\end{array}$ \\
\hline Physically abused by others & $\begin{array}{c}0.739 \\
(0.542)\end{array}$ & $\begin{array}{c}0.765 \\
(0.589)\end{array}$ & $\begin{array}{c}1.007 \\
(0.991)\end{array}$ & $\begin{array}{c}0.000 \\
(0.994)\end{array}$ \\
\hline \multicolumn{5}{|l|}{ Current Adversity: } \\
\hline Alcohol problem & $\begin{array}{c}1.002 \\
(0.955)\end{array}$ & $\begin{array}{c}0.997 \\
(0.899)\end{array}$ & $\begin{array}{c}1.005 \\
(0.874)\end{array}$ & $\begin{array}{c}0.938 \\
(0.434)\end{array}$ \\
\hline Anxiety HADSA score & $\begin{array}{c}1.196 \\
(0.461)\end{array}$ & $\begin{array}{c}2.651^{* * *} \\
(0.000)\end{array}$ & $\begin{array}{c}3.769^{* * *} \\
(0.000)\end{array}$ & $\begin{array}{c}5.573^{* * *} \\
(0.004)\end{array}$ \\
\hline Moderate or Severe Depressive Symptoms & $\begin{array}{l}1.608^{* *} \\
(0.021)\end{array}$ & $\begin{array}{c}1.291 \\
(0.229)\end{array}$ & $\begin{array}{c}1.308 \\
(0.312)\end{array}$ & $\begin{array}{c}2.147 \\
(0.183)\end{array}$ \\
\hline \multicolumn{5}{|l|}{ Demographic Controls } \\
\hline Age & $\begin{array}{c}1.373 * * * \\
(0.000)\end{array}$ & $\begin{array}{c}1.014 \\
(0.510)\end{array}$ & $\begin{array}{c}1.126^{* * *} \\
(0.000)\end{array}$ & $\begin{array}{c}0.958 \\
(0.498)\end{array}$ \\
\hline Secondary education as highest level & $\begin{array}{l}1.578^{*} \\
(0.063)\end{array}$ & $\begin{array}{c}1.114 \\
(0.647)\end{array}$ & $\begin{array}{c}0.486^{* * *} \\
(0.006)\end{array}$ & $\begin{array}{l}1.151 \\
(0.843)\end{array}$ \\
\hline Tertiary education as highest level & $\begin{array}{c}1.969^{* * *} \\
(0.010)\end{array}$ & $\begin{array}{c}0.413 * * * \\
(0.003)\end{array}$ & $\begin{array}{c}0.205^{* * *} \\
(0.000)\end{array}$ & $\begin{array}{l}0.131 * \\
(0.098)\end{array}$ \\
\hline
\end{tabular}

${ }^{*} \mathrm{p}<0.10,{ }^{* *} \mathrm{p}<0.05, * * * \mathrm{p}<0.01$

Exponentiated coefficients and p-values in parenthesis $\mathrm{n}=1473$ 
Table 3b: Multinomial logit model of effects of childhood sexual abuse on employment status Women $<65$ years old

\begin{tabular}{|c|c|c|c|c|}
\hline & Retired & Unemployed & $\begin{array}{c}\text { Permanent } \\
\text { Disabled/Sick }\end{array}$ & Others \\
\hline CSA & $\begin{array}{c}0.806 \\
(0.511)\end{array}$ & $\begin{array}{c}0.724 \\
(0.497)\end{array}$ & $\begin{array}{c}1.295 \\
(0.477)\end{array}$ & $\begin{array}{c}0.904 \\
(0.691)\end{array}$ \\
\hline \multicolumn{5}{|l|}{$\begin{array}{l}\text { Recall of childhood circumstances } \\
\text { from birth to around age 14: }\end{array}$} \\
\hline Average economic circumstances & $\begin{array}{c}1.484 \\
(0.165)\end{array}$ & $\begin{array}{c}0.629 \\
(0.183)\end{array}$ & $\begin{array}{c}0.549 \\
(0.151)\end{array}$ & $\begin{array}{c}0.915 \\
(0.670)\end{array}$ \\
\hline Poor economic circumstances & $\begin{array}{c}1.469 \\
(0.273)\end{array}$ & $\begin{array}{c}0.663 \\
(0.357)\end{array}$ & $\begin{array}{c}0.861 \\
(0.745)\end{array}$ & $\begin{array}{c}0.964 \\
(0.883)\end{array}$ \\
\hline $\begin{array}{l}\text { Father had primary education as highe } \\
\text { level }\end{array}$ & $\begin{array}{c}0.885 \\
(0.538)\end{array}$ & $\begin{array}{c}0.799 \\
(0.416)\end{array}$ & $\begin{array}{l}2.081^{* *} \\
(0.034)\end{array}$ & $\begin{array}{c}0.809 \\
(0.156)\end{array}$ \\
\hline Lived in an urban area & $\begin{array}{c}0.914 \\
(0.608)\end{array}$ & $\begin{array}{l}1.613^{* *} \\
(0.048)\end{array}$ & $\begin{array}{c}1.321 \\
(0.233)\end{array}$ & $\begin{array}{c}0.870 \\
(0.283)\end{array}$ \\
\hline Health excellent, very good or good & $\begin{array}{c}0.822 \\
(0.556)\end{array}$ & $\begin{array}{l}0.421 * * \\
(0.028)\end{array}$ & $\begin{array}{c}0.320 * * * \\
(0.001)\end{array}$ & $\begin{array}{c}0.973 \\
(0.923)\end{array}$ \\
\hline $\begin{array}{l}\text { Recall of Childhood Adversity: } \\
\text { Parents experienced a drink/drug } \\
\text { problem }\end{array}$ & $\begin{array}{l}1.017 \\
(0.952)\end{array}$ & $\begin{array}{c}0.813 \\
(0.593)\end{array}$ & $\begin{array}{c}0.985 \\
(0.966)\end{array}$ & $\begin{array}{c}0.854 \\
(0.466)\end{array}$ \\
\hline Physically abused by parents & $\begin{array}{l}1.530 \\
(0.328)\end{array}$ & $\begin{array}{c}0.647 \\
(0.578)\end{array}$ & $\begin{array}{c}1.853 \\
(0.176)\end{array}$ & $\begin{array}{c}0.844 \\
(0.650)\end{array}$ \\
\hline Physically abused by others & $\begin{array}{c}1.207 \\
(0.639)\end{array}$ & $\begin{array}{c}0.690 \\
(0.565)\end{array}$ & $\begin{array}{c}0.973 \\
(0.953)\end{array}$ & $\begin{array}{c}0.664 \\
(0.263)\end{array}$ \\
\hline Current Adversity: & & & & \\
\hline Alcohol problem & $\begin{array}{c}0.990 \\
(0.691)\end{array}$ & $\begin{array}{l}1.067^{* *} \\
(0.046)\end{array}$ & $\begin{array}{l}1.067^{* *} \\
(0.028)\end{array}$ & $\begin{array}{c}1.024 \\
(0.187)\end{array}$ \\
\hline Anxiety HADSA score & $\begin{array}{c}1.270 \\
(0.223)\end{array}$ & $\begin{array}{l}1.595^{*} \\
(0.075)\end{array}$ & $\begin{array}{c}4.770^{* * *} \\
(0.000)\end{array}$ & $\begin{array}{c}1.146 \\
(0.349)\end{array}$ \\
\hline $\begin{array}{l}\text { Moderate or Severe Depressive } \\
\text { Symptoms }\end{array}$ & $\begin{array}{c}1.189 \\
(0.508)\end{array}$ & $\begin{array}{c}0.960 \\
(0.904)\end{array}$ & $\begin{array}{c}0.705 \\
(0.327)\end{array}$ & $\begin{array}{c}0.738 \\
(0.142)\end{array}$ \\
\hline Demographic Controls & & & & \\
\hline Age & $\begin{array}{c}1.352^{* * * *} \\
(0.000)\end{array}$ & $\begin{array}{c}1.003 \\
(0.908)\end{array}$ & $\begin{array}{c}1.013 \\
(0.585)\end{array}$ & $\begin{array}{c}1.037 * * * \\
(0.003)\end{array}$ \\
\hline Secondary education as highest level & $\begin{array}{c}0.845 \\
(0.509)\end{array}$ & $\begin{array}{l}0.525^{*} \\
(0.056)\end{array}$ & $\begin{array}{l}0.605^{*} \\
(0.081)\end{array}$ & $\begin{array}{c}0.589 * * * \\
(0.003)\end{array}$ \\
\hline Tertiary education as highest level & $\begin{array}{c}1.380 \\
(0.211) \\
\end{array}$ & $\begin{array}{c}0.303 * * * \\
(0.001) \\
\end{array}$ & $\begin{array}{c}0.154^{* * *} \\
(0.000) \\
\end{array}$ & $\begin{array}{c}0.210^{* * *} \\
(0.000) \\
\end{array}$ \\
\hline
\end{tabular}

${ }^{*} \mathrm{p}<0.10,{ }^{* *} \mathrm{p}<0.05,{ }^{* * *} \mathrm{p}<0.01$

Exponentiated coefficients and $\mathrm{p}$-values in parenthesis $\mathrm{n}=1877$ 
Table 4: OLS of Effects of CSA on income

\begin{tabular}{lcc}
\hline & $\beta_{\mathrm{men}<65}$ & $\beta_{\text {women } 65}$ \\
\hline \hline Log net family income & $-0.436^{* *}$ & -0.076 \\
& $(0.170)$ & $(0.117)$ \\
Log equivalised net family income & $-0.344^{* *}$ & -0.060 \\
& $(0.170)$ & $(0.112)$ \\
Log labour income (only for employees) & -0.081 & -0.004 \\
& $(0.107)$ & $(0.101)$ \\
\hline
\end{tabular}

${ }^{*} \mathrm{p}<0.10,{ }^{* *} \mathrm{p}<0.05, * * * \mathrm{p}<0.01$

Standard errors in parenthesis

Control variables are as in Table $3 a$ and $3 b$.

Table 5: Multinomial logit regression of the effect of CSA on the living arrangements

\begin{tabular}{lccc}
\hline & $\begin{array}{c}\text { Living } \\
\text { alone }\end{array}$ & $\begin{array}{c}\text { Living } \\
\text { with } \\
\text { spouse } \\
\text { only }\end{array}$ & $\begin{array}{c}\text { Living } \\
\text { with } \\
\text { other } \\
\text { relative } \\
\text { or non- } \\
\text { relatives }\end{array}$ \\
\hline \hline Effect of CSA for men $<65$ & $2.072^{* *}$ & 1.091 & 0.258 \\
Effect of CSA for women $<65$ & $(0.030)$ & $(0.777)$ & $(0.164)$ \\
& 1.259 & 0.858 & 0.248 \\
$(0.451)$ & $(0.530)$ & $(0.121)$ \\
\hline
\end{tabular}

Reference category: living with (spouse) and children

p-values in parenthesis

Control variables are as in Table $3 \mathrm{a}$ and $3 \mathrm{~b}$.

$* \mathrm{p}<0.05, * * \mathrm{p}<0.01, * * * \mathrm{p}<0.001$ 


\section{References}

Chartier, M. J., Walker, J. R., \& Naimark, B. (2007). Childhood Abuse, Adult Health, and Health Care Utilization: Results from a Representative Community Sample. American Journal of Epidemiology, 165(9), 1031-1038.

Chen, L. P., Murad, M. H., Paras, M. L., Colbenson, K. M., Sattler, A. L., Goranson, E. N., . . Zirakzadeh, A. (2010). Sexual abuse and lifetime diagnosis of psychiatric disorders: systematic review and meta-analysis. Mayo Clin Proc, 85(7), 618-629. doi: $10.4065 / \mathrm{mcp} .2009 .0583$

Currie, J., \& Widom, C. S. (2010). Long-term consequences of child abuse and neglect on adult economic well-being. Child Maltreat, 15(2), 111-120.

Dooley, D., Prause, J., \& Ham-Rowbottom, K. A. (2000). Underemployment and Depression: Longitudinal Relationships. Journal of Health and Social Behavior, 41, 421-436.

Goodman, A., Joyce, R., \& Smith, J. P. (2011). The long shadow cast by childhood physical and mental problems on adult life. Proc Natl Acad Sci U S A, 108(15), 6032-6037. doi: 10.1073/pnas.1016970108

Hyman, B. (2000). The Economic Consequences of Child Sexual Abuse for Adult Lesbian Women. Journal of Marriage and Family, 62(1), 199-211. doi: 10.1111/j.1741-3737.2000.00199.x

Johnson, C. F. (2004). Child sexual abuse. Lancet, 364, 462-470.

Mayfield, D., McLeod, G., \& Hall, P. (1974). The CAGE questionnaire: validation of a new alcoholism screening instrument. Am J Psychiatry, 131(10), 1121-1123.

McGee, H., Garavan, R., Byrne, J., O'Higgins, M., \& Conroy, R. (2011). Secular trends in child and adult sexual violence--one decreasing and the other increasing: a population survey in Ireland. Eur J Public Health, 21(1), 98-103. doi: 10.1093/eurpub/ckp203

McGee, H., Garavan, R., DeBarra, M., Byrne, J., \& Conroy, R. (2002). The SAVI Report. Sexual Abuse and Violence in Ireland. A national study of Irish experiences, beliefs and attitudes concerning sexual violence. Dublin Liffey Press.

Molnar, B. E., Buka, S. L., \& Kessler, R. C. (2001). Child sexual abuse and subsequent psychopathology: results from the National Comorbidity Survey. Am J Public Health, 91(5), 753-760.

Murphy, Y. (2009). Report by Commission of Investigation into the Catholic Archdiocese of Dublin. Dublin.

Radloff, L. S. (1977). The CES-D scale: a self report depression scale for research in the general population. Applied Psychological Measurement, 1, 385-401.

Rind, B., \& Tromovitch, P. (1997). A meta-analytic review of findings from national samples on psychological correlates of child sexual abuse. Journal of Sex Research, 34(3), 237-255.

Rind, B., Tromovitch, P., \& Bauserman, R. (1998). A meta-analytic examination of assumed properties of child sexual abuse using college samples. Psychological Bulletin, 124(1), 22-53.

Robst, J., \& Smith, S. (2008). The Effect of Childhood Sexual Victimization on Women's Income. Eastern Economic Journal, 34(1), 27-40. doi: http://www.palgrave-journals.com/eej/archive/

Ryan, S. (2009). Final Report of the Commission to Inquire into Child Abuse. Dublin: Stationary Office.

Savoca, E., \& Rosenheck, R. (2000). The civilian labor market experiences of Vietnam-era veterans: the influence of psychiatric disorders. Journal of Mental Health and Policy Economics, 3, 199-207.

Smith, J. P., \& Smith, G. C. (2010). Long-term economic costs of psychological problems during childhood. Social Science \& Medicine, 71(1), 110-115. doi: http://dx.doi.org/10.1016/j.socscimed.2010.02.046 